\title{
Knowledge of the Egyptian emergency physicians about the use of rt-PA in acute ischemic stroke
}

\author{
Mohamed El-Sayed El-khatib ${ }^{1}$, Shereen Ahmed El Ahwal' ${ }^{2}$, Muhammad Masoud ${ }^{1}$ and Sherine El Mously ${ }^{1 *}$ (D
}

\begin{abstract}
Background: The administration of recombinant tissue plasminogen activator (rt-PA) has increased the focus on acute ischemic stroke (AIS) as an emergency condition. The emergency physicians have to rapidly recognize the patients who are candidates for rt-PA and refer them to the specialized stroke team within the proper time window. The knowledge of the emergency physicians about the benefit and the drawbacks of this therapy is crucial and it affects their attitudes towards its use.
\end{abstract}

Objective: To apply a survey on the Egyptian emergency physicians aiming to investigate their knowledge about the use rt-PA therapy in AlS.

Methodology: A self-administered questionnaire was sent to the emergency physicians who are working in three Egyptian governorates.

Results: Out of 120 emergency physicians, the total knowledge of the study group was good with a score of $7 \pm$ 1.8/11. Most of the participants mentioned the correct answers (over 50\%) for all items except for one question regarding the blood glucose control before the use of rt-PA. Significant positive correlation was noted between the knowledge score and the age.

Conclusions: The surveyed emergency physicians had a good knowledge about the use of rt-PA in AIS, yet, this knowledge is mainly theoretical. Therefore, tutorials, clinical training, and active engagement in the stroke care team are warranted to improve their clinical practice.

Keywords: Acute ischemic stroke, rt-PA, Emergency physicians, Knowledge, Egypt

\section{Introduction}

Cerebrovascular stroke (CVS) is considered the second leading cause of death and dementia [1]. Although it is a major health problem in the Egyptian population, there is no active nationwide registry for CVS and, consequently, accurate data on its epidemiology are scarce [2].

Nowadays, acute ischemic stroke (AIS) is a treatable condition with great influence on the patients' survival and recovery [3]. The administration of intravenous

\footnotetext{
* Correspondence: smm02@fayoum.edu.eg

${ }^{1}$ Faculty of Medicine, Fayoum University, Keman Fares Area, Fayoum City 63611, Egypt

Full list of author information is available at the end of the article
}

thrombolysis using the recombinant tissue plasminogen activator (rt-PA) has increased the focus on AIS as an emergency condition $[4,5]$. In order to get the maximum benefit from rt-PA therapy, prehospital delay and onset to treatment time (OTT) have to be minimized [6].

Emergency physicians have a crucial role in the stroke care system. They have to rapidly recognize the patients who are candidates for thrombolysis through performing a brain imaging and referring those patients to the specialized stroke team within the proper time window. In rural areas, with a lack of on-site stroke expertise, emergency physicians might take the upper hand in the administration of rt-PA with the support of a remote neurology consultation [7-10].

\section{Springer Open}

(c) The Author(s). 2020 Open Access This article is licensed under a Creative Commons Attribution 4.0 International License, which permits use, sharing, adaptation, distribution and reproduction in any medium or format, as long as you give appropriate credit to the original author(s) and the source, provide a link to the Creative Commons licence, and indicate if changes were made. The images or other third party material in this article are included in the article's Creative Commons licence, unless indicated otherwise in a credit line to the material. If material is not included in the article's Creative Commons licence and your intended use is not permitted by statutory regulation or exceeds the permitted use, you will need to obtain permission directly from the copyright holder. To view a copy of this licence, visit http://creativecommons.org/licenses/by/4.0/. 
Although most major general hospitals could supply an infrastructure for the rt-PA therapy, physicians' insufficient knowledge may contribute to a diminished use of this valuable therapy. As an example, many physicians would overemphasize the intracranial hemorrhage as an adverse effect associated with this therapy [11]. Consequently, the physicians' attitude would have a negative impact on the patients or their families. The later will likely refuse the rt-PA therapy after consultation [12].

In this study, we aimed to apply a survey on the Egyptian emergency physicians to investigate their knowledge about the use of intravenous rt-PA therapy in AIS.

\section{Methodology}

The present study was based on a self-administered questionnaire that was designed after reading different international reviews and researches [10, 12, 13].

This cross-sectional study was conducted from January to June 2019. It targeted all the physicians who are working in the emergency departments of Fayoum University Hospitals and Fayoum General Hospital in Fayoum Governorate; Abu Qir Central Hospital in Alexandria Governorate; Tanta University Hospitals, El Menshawy General Hospital and El Santa Central hospital in Gharbia governorate. All emergency physicians who participated in the study are currently licensed by the Ministry of Health.

The questionnaire was sent personally through data collectors or via e-mails. The first part of the questionnaire included the demographic data and the basic characteristics of the physicians' cohort (age, sex, specialty, and duration of experience in years). The second part that is formed of 8 items explored the knowledge about the manifestations of AIS (cranial nerves, extremities, and speech deficits added to time of onset). Finally, the third part consisted of 11 multiple choice questions (MCQ) covering the knowledge about the use of rt-PA within $4.5 \mathrm{~h}$ from the onset of AIS. A 3-point scale was used in this MCQ (true, false, and do not know) in which the correct answer was scored 1, while do not know and the wrong answer were scored 0 with a maximum total score of 11 . The questionnaire was piloted on 30 respondents for its acceptability and reliability. It was subjected for editing through re-writing, adding, and deleting some questions. For the assessment of internal consistency, Cronbach's alpha was used with $\alpha=0.79$.

\section{Statistical analysis}

The collected data were organized, tabulated, and statistically analyzed using the IBM Statistical Package for Social Sciences (SPSS) software version 22 (2013, USA). Data were presented as mean \pm standard deviation (SD) for continuous variables and frequency with percentages was used for categorical variables. To determine the relation between different quantitative variables, Spearman's correlation was performed. Linear regression was applied to determine the predictors of the knowledge score. Also, logistic regression was performed to identify the predictors of the knowledge score. A $p$ value $\leq 0.05$ was considered statistically significant.

\section{Results}

The current study included 120 emergency physicians. Their general characteristics are shown in Table 1.

Concerning the second part of the questionnaire, all the participants (neuropsychiatry, internal medicine, and cardiology residents) knew the manifestations of AIS.

Regarding the third part of the questionnaire, the total knowledge of the study group was generally good with a total score of $7 \pm 1.8 / 11$. Most of the participants mentioned the correct answers (over 50\%) for all items except for one question about the blood glucose control before using rt-PA (6.7\%). Concerning the correct answers about rt-PA therapy, $63.3 \%$ of the study population knew that it is a legislated drug, $96.7 \%$ knew that it is used in the treatment of AIS, and 90\% answered that it is the best possible treatment option for AIS. Only $53.3 \%$ were aware of the window period for rt-PA. Finally, $70 \%$ answered correctly that the best treatment route for AIS is intravenous. Further details are illustrated in Table 2.

The mean knowledge score was higher among the residents of neuropsychiatry $(8.6 \pm 1.6 / 11)$ compared to others $(6.4 \pm 1.5 / 11)$ with statistical significance $(p<$ $0.0001)$. On the other hand, the mean knowledge score was higher in females compared to males $(7.2 \pm 1.8$ vs. $6.5 \pm 1.9 / 11)$, but it did not reach a statistical significance $(p=0.113)$.

There was a statistically significant positive correlation between the knowledge score and the age $(r=0.198, p=$ 0.03). However, no other correlation reached a statistical

Table 1 Distribution of all physicians by background characteristics

\begin{tabular}{lll}
\hline Age & $\boldsymbol{N}(120)$ & $\%$ \\
Mean \pm SD & $25.7 \pm 1.9$ \\
Sex & & \\
Male & 24 & 20 \\
Female & 96 & 80 \\
Duration of experience in years & & \\
Mean \pm SD & $2.1 \pm 1.6$ \\
Specialty & & 30 \\
Neuropsychiatry residents & 36 & 70 \\
Others (residents of internal medicine and cardiology) & 84 & \\
\hline$N$
\end{tabular}

$N$ number, \% percentage, SD standard deviation 
Table 2 Percent distribution of all participants according to knowledge $(N=120)$

\begin{tabular}{|c|c|c|c|c|c|c|}
\hline & \multicolumn{2}{|c|}{ True } & \multicolumn{2}{|c|}{ False } & \multicolumn{2}{|c|}{$\begin{array}{l}\text { Do not } \\
\text { know }\end{array}$} \\
\hline & N & $\%$ & N & $\%$ & N & $\%$ \\
\hline Is rt-PA, used in the treatment of AIS, a legislated drug? & 76 & 63.3 & 4 & 3.3 & 40 & 33.3 \\
\hline Can rt-PA be used in the treatment of AIS? & 116 & 96.7 & 4 & 3.3 & 0 & 0.0 \\
\hline Is rt-PA the best possible treatment option of AIS? & 108 & 90 & 12 & 10 & 0 & 0.0 \\
\hline $\begin{array}{l}\text { Is antiplatelet agent alone or in combination with a neuroprotective agent is the best possible treatment } \\
\text { option of AIS? }\end{array}$ & 80 & 66.7 & 28 & 23.3 & 12 & 10 \\
\hline Is heparin the best possible treatment option of AIS? & 96 & 80 & 12 & 10 & 12 & 10 \\
\hline Are neuroprotective agents such as citicholine or edavarone the best possible treatment option of AIS? & 76 & 63.3 & 8 & 6.7 & 36 & 30 \\
\hline Is the Window period for rt-PA $4.5 \mathrm{~h}$ ? & 64 & 53.3 & 52 & 43.3 & 4 & 3.3 \\
\hline Is Intravenous thrombolytic therapy for AIS the best treatment route of AIS? & 84 & 70 & 4 & 3.3 & 32 & 26.7 \\
\hline Do we have to control the blood pressure in AIS before using rt-PA? & 72 & 60 & 16 & 13.3 & 32 & 26.7 \\
\hline Do we have to control the blood glucose level in AIS before using rt-PA? & 8 & 6.7 & 80 & 66.7 & 32 & 26.7 \\
\hline Are intravenous fluids used in AIS? & 64 & 53.3 & 36 & 30 & 20 & 16.7 \\
\hline Total score (11) & Mea & ก $7 \pm$ & 1.8 & & & \\
\hline
\end{tabular}

$N$ number, $\%$ percentage, $r t-P A$ recombinant tissue plasminogen activator, $A / S$ acute ischemic stroke

significance using the Spearman correlation. Meanwhile, the multiple linear regression analysis revealed that specialty and age were significant predictors of knowledge score $(p<0.05)$ as shown in Table 3.

\section{Discussion}

Emergency physicians are often the first contacts with the AIS patients and their attitude towards rt-PA is a critical factor in the use or non-use of this treatment. Emergency physicians help in shaping the treatment protocols and their perceptions influence the attitudes of others [14].

The total knowledge of all the physicians included in the study was $7 \pm 1.8 / 11$. Most of them mentioned the correct answers (over 50\%) for all items except for one question regarding the blood glucose control before using rt-PA. These results agree with those obtained in a previous study [15] where the authors observed greater acceptance for thrombolysis in AIS. Nearly all respondents characterized rt-PA therapy as either ideal or acceptable and approximately one-quarter indicated that its use represented a legal standard of care in eligible
AIS patients. The majority (83\%) indicated that they would use rt-PA when the ideal setting is provided at their local hospitals.

Older surveys provided acceptance estimates ranging from 53 to $60 \%[16,17]$. Possible explanations for these findings include positive changes in the attitudes towards the AIS treatment, differences in the survey cohort compared to prior studies, and differences in the surveys' design.

Our results showed that the mean knowledge score was significantly higher among the residents of neuropsychiatry compared to others. This is in concordance with Alharbi and co-authors [18] who reported that $72.8 \%$ of the neurology residents support the use of rtPA in AIS patients. Also, higher acceptance rates (90.1\%) were found among the Chinese neurologists as reported by Wang and his colleagues [19]. This increased acceptance may be attributed to the increasing evidence supporting the validity and effectiveness of thrombolytic therapy [20].

However, Ma and his group [12] showed that the mean accuracy rate of the provided questions pertaining

Table 3 Multiple linear regression showing predictors of knowledge score

\begin{tabular}{|c|c|c|c|c|c|}
\hline & \multirow[t]{2}{*}{$\beta$} & \multirow[t]{2}{*}{$t$} & \multirow[t]{2}{*}{$p$} & \multicolumn{2}{|c|}{ 95\% confidence interval for $\boldsymbol{B}$} \\
\hline & & & & Lower bound & Upper bound \\
\hline Constant & 5.409 & 2.723 & 0.007 & 1.474 & 9.343 \\
\hline Sex & 0.328 & 0.917 & 0.361 & -0.381 & 1.037 \\
\hline Specialty & -2.194 & -7.252 & $<0.0001$ & -2.793 & -1.595 \\
\hline Experience in years & -0.124 & -1.372 & 0.173 & -0.304 & 0.055 \\
\hline Age in years & 0.196 & 2.661 & 0.009 & 0.05 & 0.342 \\
\hline
\end{tabular}

$\beta$ beta coefficient, $t t$ value, $p p$ value 
the physicians' knowledge about rt-PA displayed a broad range (0.8 to $96.2 \%$ ), and the mean total score for respondents was very low. Although the participants were neurologists, they had poor knowledge about the use of rt-PA in AIS. The researchers attributed their results to the low rate of fibrinolytic therapy's use in China.

Our results showed that the mean knowledge score was higher in females compared to males, but it did not reach a statistical significance. This result needs further investigation to find out whether there is sex predominance or there are any unexplored factors affecting this association.

Furthermore, there was a significant positive correlation between the knowledge score and the age. This finding is in agreement with Alharbi and colleagues [18] who showed that the confidence was significantly more likely to be reported by the senior rather than the junior residents. This could be reasonably explained by to the duration of clinical experience and the increased knowledge about rt-PA that is expected to be higher among the seniors.

Multiple linear regression analysis showed that the significant predictors of the study population knowledge were the specialty and age. These findings were in agreement with Scott and co-authors [21] who showed that there was a greater acceptance of rt-PA among the older and non-emergency medicine trained physicians.

Conversely, Grady and his colleagues [15] reported that almost half of the respondents in their survey supported the use of rt-PA in AIS and only $20 \%$ of them highly agreed its use. Respondents were nearly four times more likely to agree on its use only if they received guidance from a professional consultant.

Our study was limited by the following: the questionnaire was simply designed and did not include all aspects of knowledge regarding the rt-PA therapy. The reason behind this was our aim to make the questionnaire more convenient and to get a higher response rate. However, if respondents attained maximal scores in this questionnaire, they might not manage optimally in clinical practice. Another limitation is that the neuropsychiatry residents in the university hospitals consisted only of $30 \%$ of the study group and were not representing the physicians throughout the whole country. It would have been more optimal to obtain further data through a wider cooperation with other hospitals around the country. Finally, given the recent historical implementation of stroke care units in Egypt, caution is warranted in generalizing the results obtained in our study.

\section{Conclusions}

The emergency physicians are the cornerstones in the stroke care system. Their knowledge towards the use of rt-PA in AIS is crucial in order to recognize and refer the AIS patients in the proper time window. Fortunately, nearly all Egyptian emergency physicians who responded to this survey indicated that rt-PA use in eligible patients is ideal and acceptable. It is mandatory for all Egyptian emergency physicians to be involved, educated, and engaged in the stroke care system to enhance their clinical practice especially after the recent implementation of several stroke units across Egypt.

\section{Abbreviations \\ AIS: Acute ischemic stroke; CVS: Cerebrovascular stroke; MCQ: Multiple choice questions; OTT: Onset to treatment time; rt-PA: Recombinant tissue plasminogen activator; SD: Standard deviation; SPSS: Statistical package for social sciences}

\section{Acknowledgements \\ Not applicable.}

\section{Authors' contributions}

MM planned the design of the questionnaire and he performed the statistical analysis. MS and SA distributed the questionnaire and collected the data. MS wrote the manuscript and then SM revised and finalized it. SM is responsible also for the publication. The author(s) read and approved the final manuscript.

\section{Funding}

No funding was obtained from any institution for our study.

Availability of data and materials

Data can be available for publication only by special approval from Fayoum University.

\section{Ethics approval and consent to participate}

The study was revised and approved by the Research Ethical Committee of the Faculty of Medicine, Fayoum University (Number: R76) on 16 September 2018. All included physicians were informed about the aim of the study and the content of the questionnaire. They signed an informed consent before starting the survey. The confidentiality of their information and their right not to participate in the study were both respected.

\section{Consent for publication}

Not applicable.

\section{Competing interests}

None of the authors have any competing interests (financial or nonfinancial).

\section{Author details \\ ${ }^{1}$ Faculty of Medicine, Fayoum University, Keman Fares Area, Fayoum City 63611, Egypt. ${ }^{2}$ Faculty of Medicine, Tanta University, Tanta, Egypt.}

Received: 7 May 2020 Accepted: 10 June 2020

Published online: 29 June 2020

\section{References}

1. Soler EP, Ruiz VC. Epidemiology and risk factors of cerebral ischemia and ischemic heart diseases: similarities and differences. Curr Cardiol Rev. 2010; 6(3):138-49.

2. Abd-Allah F, Khedr E, Oraby MI, Bedair AS, Georgy SS, Moustafa RR. Stroke burden in Egypt: data from five epidemiological studies. Int J Neurosci. 2018;128(8):765-71.

3. Bath PMW, Lees KR. Acute stroke. West J Med. 2000;173(3):209-12.

4. Lees KR, Bluhmki E, von Kummer R, Brott TG, Toni D, Grotta JC, et al. Time to treatment with intravenous alteplase and outcome in stroke: an updated pooled analysis of ECASS, ATLANTIS, NINDS, and EPITHET trials. Lancet. 2010; 375(9727):1695-703.

5. Fransen PS, Berkhemer OA, Lingsma HF, Beumer D, van den Berg LA, Yoo $\mathrm{AJ}$, et al. Time to reperfusion and treatment effect for acute ischemic stroke: a randomized clinical trial. JAMA Neurol. 2016;73(2):190-6. 
6. Faiz KW, Sundseth A, Thommessen B, Rønning OM. Patient knowledge on stroke risk factors, symptoms and treatment options. Vasc Health Risk Manag. 2018;14:37-40.

7. Morris DL, Rosamond W, Madden K, Schultz C, Hamilton S. Prehospital and emergency department delays after acute stroke: the Genentech stroke presentation survey. Stroke. 2000;31(11):2585-90.

8. Centers for Disease Control and Prevention (CDC). Pre-hospital and hospital delays after stroke onset-- United States, 2005-2006. MMWR Morb Mortal Wkly Rep. 2007;56(19):474-8.

9. Heikkilä I, Kuusisto H, Stolberg A, Palomäki A. Stroke thrombolysis given by emergency physicians cuts in-hospital delays significantly immediately after implementing a new treatment protocol. Scand J Trauma Resusc Emerg Med. 2016;24:46.

10. AlKhathaami AM, Aloraini H, Almudlej S, Al Issa H, Elshammaa N, Alsolamy S. Knowledge and attitudes of saudi emergency physicians toward t-PA use in stroke. Neurol Res Int. 2018;2018:3050278.

11. Wang Y, Liao X, Zhao X, Wang DZ, Wang C, Nguyen-Huynh MN, et al. Using recombinant tissue plasminogen activator to treat acute ischemic stroke in china: analysis of the results from the Chinese National Stroke Registry (CNSR). Stroke. 2011;42(6):1658-64.

12. Ma L, Niu X, Zhang W, Fang Y, Wang J. Assessment of neurologists' knowledge regarding intravenous fibrinolytic therapy for acute stroke in Shanxi province in China. BMC Health Serv Res. 2017;17(1):358.

13. Aaron S, Alexander M, Maya T, Mathew V, Goyal M. Treatment of acute ischemic stroke: awareness among general practitioners. Neurol India. 2010; 58(3):441-2.

14. Jauch EC, Saver JL, Adams HP Jr, Bruno A, Connors JJ, Demaerschalk BM, et al. Guidelines for the early management of patients with acute ischemic stroke: a guideline for healthcare professionals from the American Heart Association/American Stroke Association. Stroke. 2013;44(3):870-947.

15. Grady AM, Bryant J, Carey ML, Paul CL, Sanson-Fisher RW, Levi CR. Agreement with evidence for tissue plasminogen activator use among emergency physicians: a cross-sectional survey. BMC Res Notes. 2015;8:267.

16. Brown DL, Barsan WG, Lisabeth LD, Gallery ME, Morgenstern LB. Survey of emergency physicians about recombinant tissue plasminogen activator for acute ischemic stroke. Ann Emerg Med. 2005;46(1):56-60

17. Somerfield J, Barber P, Anderson N, Spriggs D, Charleston A, Bennett P. Changing attitudes to the management of ischaemic stroke between 1997 and 2004: a survey of New Zealand physicians. Intern Med J. 2006;36(5): 276-80

18. Alharbi FA, Maghfuri NM, Abdu DM, Redine MY. Saudi neurology residents' knowledge and attitudes toward intravenous thrombolysis in patients with acute ischemic stroke. J Family Med Prim Care. 2020;9(1):192-6.

19. Wang MD, Yin XX, Yang $T$, Wang $Y$, Zhu YY, Zhou YF, et al. Chinese neurologists' perspective on intravenous thrombolysis for acute ischemic stroke. Brain Behav. 2017;8(1):e00882.

20. Fugate $J E$, Rabinstein $A A$. Update on intravenous recombinant tissue plasminogen activator for acute ischemic stroke. Mayo Clin Proc. 2014;89(7): 960-72.

21. Scott PA, Xu Z, Meurer WJ, Frederiksen SM, Haan MN, Westfall MW, et al. Attitudes and beliefs of Michigan emergency physicians toward tissue plasminogen activator use in stroke: baseline survey results from the INcreasing Stroke Treatment through INteractive behavioral Change Tactic (INSTINCT) trial hospitals. Stroke. 2010;41(9):2026-32.

\section{Publisher's Note}

Springer Nature remains neutral with regard to jurisdictional claims in published maps and institutional affiliations.

\section{Submit your manuscript to a SpringerOpen ${ }^{\circ}$ journal and benefit from:}

- Convenient online submission

- Rigorous peer review

- Open access: articles freely available online

- High visibility within the field

- Retaining the copyright to your article

Submit your next manuscript at $\boldsymbol{\nabla}$ springeropen.com 